lung pathology and cultures of respiratory secretions.

Numerous studies have been performed in this area in recent years in an attempt to clarify the diagnostic approach to the socalled "ventilator-associated pneumonia". It would be unfortunate if such efforts were wasted simply because of misinterpretation. The practical issue for physicians who care for patients on mechanical ventilation is to learn how much they can rely on the sampling technique(s) they routinely use when pulmonary infection is suspected. Taken together, the studies by Torres $\mathrm{et} \mathrm{al}$ and others simply suggest that tracheal aspirates are just as good as other more "sophisticated" techniques using quantitative cultures and/or protected specimens, with or without bronchoscopy. I have already mentioned the potential impact of this approach on antibiotic usage in intensive care units and its consequences. But are we 25 years behind with diagnostic techniques of pulmonary infection?

C BRUN-BUISSON Hôpital Henri Mondor Université Paris XI 94010-Créteil France

1 Torres A, El Ebiary M, Padro L, Gonzales J, de la Bellacasa JP, Ramirez J, et al. Validation of different techniques for the diagnosis of ventilator-associated pneumonia. Comparison with immediate post-mortem biopsy. $A m \mathcal{F}$ Respir Crit Care Med 1994;149:324-31.

2 Rouby JJ, Martin de Lassale E, Poete P, Nicolas MH, Bodin L, Jarlier V, et al. Nosocomial bronchopneumonia in the critically ill: histologic and bacteriologic aspects. Am Rev Respir Dis 1992;146:1059-66.

3 Marquette CH, Copin MC, Wallet F, Neviere R, Saulnier F, Mathieu D, et al. Diagnostic tests for pneumonia in ventilated patients: prospective evaluation of diagnostic accuracy using histology as a diagnostic gold standard Am $\mathcal{F}$ Respir Crit Care Med 1995;151:1878-88.

4 Chastre J, Viau F, Brun P, Pierre J, Dauge MC, Bouchama A, et al. Prospective evaluation of the protected specimen brush for the diagnosis the protected specimen brush for the diagnosis Am Rev Respir Dis 1984;130:924-9.

5 Johanson WG, Seidenfeld JJ, Gomez P, De Los Santos R, Coalson JJ. Bacteriologic diagnosis of nosocomial pneumonia following prolonged mechanical ventilation. Am Rev Respir Dis 1988;137:259-64.

6 Hill JD, Ratliff JL, Parrott JCW, Lamy M, Fallat RJ, Koeniger E, et al. Pulmonary pathology in acute respiratory insufficiency: lung biopsy as a diagnostic tool. $\mathcal{f}$ Thorac Cardiovasc Surg 1976;71:64-71.

7 Johanson WG, Pierce AK, Sanford JP, Thomas GD. Nosocomial respiratory tract infection
with gram-negative bacilli. The significance of with gram-negative bacilli. The significance of Med 1972;77:701-6.

\section{Silica exposure and risk of lung cancer}

The objective review by Weill and McDonald (January 1996;51:97-102) of the role of silica exposure and the risk of lung cancer was long overdue and thoroughly needed. The authors endorse, albeit to a limited extent, the study by Checkoway et al of diatomite workers, ${ }^{1}$ but in doing so they do not mention a most important observation that casts doubt on the alleged excess risk of lung cancer in the diatomite cohort. Thus, the overall SMR for lung cancer was $1 \cdot 43$, a figure which supports a mildly increased risk. Lacking a smoking history and in an effort to control the con- founding effects of smoking, the authors calculated the SMRs for other cigarette smoke "induced" cancers - namely, those of the larynx, bladder, kidney, and oesophagus and found no increase. While all of these cancers are related to cigarette smoking to some extent, the association is much more tenuous than it is for lung cancer. Other factors, in particular alcohol and diet, also have a significant effect. In contrast, the SMR for emphysema for the diatomite workers was 180 , indicating a greater risk of dying from emphysema than from lung cancer. The cause and effect relationship between cigarette smoking and emphysema is as compelling, if not more so, than it is between lung cancer and smoking. Moreover, there is virtually no cause of disabling emphysema leading to death other than cigarette smoking.

Weill and McDonald correctly cast doubt on studies that rely on subjects selected from silicosis registries or from registers of those who have been compensated. One of the papers referred to is that of $\mathrm{Ng}$ et al who studied subjects with silicosis in Singapore. ${ }^{2}$ The paper stated that over $90 \%$ of their cohort were smokers, compared with $60 \%$ of the general population. It is difficult to understand how so many studies that rely on silicosis registries and their like find their way into print. The question as to whether exposure to silica per se or silicosis is associated with an increased rate of lung cancer cannot be answered by statistical manipulation of defective data; statistics obviously have a role to play but, as Bradford Hill pointed out many years ago, only in conjunction with other criteria, the most important of which is biological plausibility.

WKC MORGAN
RB REGER
Chest Diseases Unit,
London Health Sciences Centre,
London,
Ontario,
Canada
$N 6 A 5 A 5$

1 Checkoway H, Heyer NJ, Demers PA, Breslow NE. Mortality among workers in the diatomaceous earth industry. $\mathrm{Br} \mathcal{F}$ Ind Med 1993;50: 586-97.

$2 \mathrm{Ng}$ TP, Chan SL, Lee J. Mortality of a cohort of men in a silicosis register: further evidence of an association with lung cancer. $A m \mathcal{F}$ Ind Med 1990;17:163-71.

\section{BOOK REVIEW}

Tobacco and Health. Scientific editors: Sir Richard Doll and Sir John Crofton. (Pp 227; $£$ 45.00). London: Royal Society of Medicine Press Ltd, 1996. 1853152722.

This book, edited by two of the most eminent men in the field, is composed of 17 chapters by current contributors in the area of smoking and health.

The chapters on price and consumption of tobacco by Townsend, on tobacco and the developing world by Mackay and Crofton, and on children and smoking: the family circle by Charlton are particularly pertinent and well written. Epidemiology and mortality are presented in two clear, easily digested chapters by Wald, Peto and co-authors. Sir
Richard Doll deals with cancers weakly related to smoking. Authors from the Bart's group spell out the harm from passive smoking and evidence of its effects on the respiratory and cardiovascular systems as well as during pregnancy.

The chapters by Reid on tobacco control, Chapman on advertising, and Pollock on the tobacco industry make stimulating, informative reading and are complemented by accounts of the current legal position of tobacco and of the industry's tactics.

There are informative chapters on smokeless tobacco, the history of tobacco substitutes, and the moves to reduce tar and nicotine levels. Baron provides a balanced discussion of the putative beneficial effects of nicotine and cigarette smoking, and a chapter is devoted to women as a vulnerable target group. The overview of cessation by Foulds is a competent account delivered from the viewpoint of a psychologist in the field, but perhaps more space could have been given to work and progress with patients.

This readable book is up to date, comprehensive, and well referenced. It is likely to be of interest to a wider audience than just medics, paramedics, public health experts, psychologists, and students who wish to be well informed. I recommend it not just to interested individuals, hospital and university libraries, but also to the general public. IAC

\section{NOTICES}

\section{International Lung Sounds Association}

The 21st International Conference on Lung Sounds will be held in Chester, UK on 4-6 September 1996. For further information please contact Raymond L H Murphy Jr, Faulkner Hospital, 1153 Centre Street, Boston, MA 02130, USA (Telephone: 617 522-5800, $\times 1968$; Fax: 617 522-4156) or John Earis, Liverpool Medical Institution, 114 Mount Pleasant, Liverpool L3 5SR, UK (Telephone: 151709 9125; Fax: 151 707 2810). Internet address: HTTP://WWW. UMANITOBA.CA/FACULTIES/ MEDICINE/PEDIATRICS AND CHILD HEALTH/ILSA/

\section{4th International Congress on the Immune Consequences of Trauma, Shock and Sepsis}

The 4th International Congress on the Immune Consequences of Trauma, Shock and Sepsis - Mechanisms and Therapeutic Approaches will be held in Munich on 4-8 March 1997. The deadline for abstracts is 30 October 1996. For further information contact Prof Dr med E Faist, Ludwig-Maximilians-University Munich, Klinikum Grosshadern, Dept. of Surgery, Marchioninistrasse 15, 81377 Munich, Germany. Phone: 49-897095-3441/2461. Fax: 49-89-7095-2460. E-mail: faist@gch.med.uni-muenchen.de. 